\title{
Colorectal cancer risk variants at 8q23.3 and 11q23.1 are associated with disease phenotype in $A P C$ mutation carriers
}

\author{
Z. Ghorbanoghli ${ }^{1,2} \cdot$ M. H. Nieuwenhuis ${ }^{1} \cdot$ J. J. Houwing-Duistermaat ${ }^{3}$ • \\ S. Jagmohan-Changur ${ }^{4}$ - F. J. Hes ${ }^{5}$ - C. M. Tops ${ }^{5}$ - A. Wagner $^{6}$ - C. M. Aalfs ${ }^{7}$ • \\ S. Verhoef ${ }^{8}$ - E. B. Gómez García ${ }^{9}$ R. H. Sijmons ${ }^{10} \cdot$ F. H. Menko ${ }^{11}$. \\ T. G. Letteboer ${ }^{12} \cdot$ N. Hoogerbrugge ${ }^{13} \cdot$ T. van Wezel $^{14}$ - H. F. A. Vasen ${ }^{1,2}$. \\ J. T. Wijnen ${ }^{4,5}$
}

Published online: 15 February 2016

(c) The Author(s) 2016. This article is published with open access at Springerlink.com

\begin{abstract}
Familial adenomatous polyposis (FAP) is a dominantly inherited syndrome caused by germline mutations in the $A P C$ gene and characterized by the development of multiple colorectal adenomas and a high risk of developing colorectal cancer (CRC). The severity of polyposis is correlated with the site of the $A P C$ mutation. However, there is also phenotypic variability within families with the same underlying $A P C$ mutation, suggesting that additional factors influence the severity of polyposis. Genome-wide association studies identified several single nucleotide polymorphisms (SNPs) that are associated with CRC. We assessed whether these SNPs are associated with polyp multiplicity in proven $A P C$ mutation carriers. Sixteen CRC-associated SNPs were analysed in a cohort of $419 A P C$ germline mutation carriers from 182 families. Clinical data were retrieved from the Dutch Polyposis Registry. Allele fre-
\end{abstract}

Z. Ghorbanoghli

z.ghorbanoghli@gmail.com

1 Netherlands Foundation for the Detetion of Hereditary Tumors, Leiden, The Netherlands

2 Department of Gastroenterology and Hepatology, Leiden University Medical Centre, Rijnsburgerweg 10, 2333 AA Leiden, The Netherlands

3 Department of Medical Statistics and Bioinformatics, Leiden University Medical Center, Leiden, The Netherlands

4 Department of Human Genetics, Leiden University Medical Center, Leiden, The Netherlands

5 Department of Clinical Genetics, Leiden University Medical Center, Leiden, The Netherlands

6 Department of Clinical Genetics, Erasmus Medical Center, Rotterdam, The Netherlands

7 Department of Clinical Genetics, Amsterdam Medical Centre, Amsterdam, The Netherlands quencies of the SNPs were compared for patients with $<100$ colorectal adenomas versus patients with $\geq 100$ adenomas, using generalized estimating equations with the $A P C$ genotype as a covariate. We found a trend of association of two of the tested SNPs with the $\geq 100$ adenoma phenotype: the C alleles of rs16892766 at 8q23.3 (OR 1.71, $95 \%$ CI $1.05-2.76, p=0.03$, dominant model) and rs3802842 at 11q23.1 (OR 1.51, $95 \%$ CI 1.03-2.22, $p=0.04$, dominant model). We identified two risk variants that are associated with a more severe phenotype in APC mutation carriers. These risk variants may partly explain the phenotypic variability in families with the same $A P C$ gene defect. Further studies with a larger sample size are recommended to evaluate and confirm the phenotypic effect of these SNPs in FAP.

Keywords Familial adenomatous polyposis - Cancer genetics $\cdot$ Colonic adenomas $\cdot$ Genetic polymorphisms

8 Family Cancer Clinic, the Netherlands Cancer Institute, Amsterdam, The Netherlands

9 Department of Clinical Genetics, University of Maastricht, Maastricht, The Netherlands

10 Department of Genetics, University Medical Centre Groningen, University of Groningen, Groningen, The Netherlands

11 Department of Clinical Genetics, VU University Medical Center, Amsterdam, The Netherlands

12 Department of Medical Genetics, University Medical Centre Utrecht, Utrecht, The Netherlands

13 Department of Human Genetics, Radboud University Nijmegen Medical Center, Nijmegen, The Netherlands

14 Departments of Pathology, Leiden University Medical Center, Leiden, The Netherlands 


\section{Introduction}

Familial adenomatous polyposis (FAP) is a hereditary colorectal cancer (CRC) susceptibility syndrome, caused by germline mutations in the adenomatous polyposis coli $(A P C)$ gene, which is located on chromosome 5. Carriers of mutations in the APC gene develop multiple colorectal adenomas and consequently have a high risk of developing $\mathrm{CRC}$. The risk of CRC in these individuals is related to the number of colorectal adenomas [1]. The severity of polyposis, reflected by the number of colorectal adenomas and the age of onset, is correlated with the site of the $A P C$ mutation [2]. Most patients with mutations in the codon 1250-1464 region develop thousands of colorectal adenomas in the first or second decades of life. Patients with a mutation at either end or in a specific splice site region of the APC gene (codons <157, 312-412, >1595) usually have an attenuated polyposis phenotype, with less than a hundred polyps and an age of onset in the third or fourth decades. The majority of FAP patients have mutations in the remainder of the gene and develop hundreds to thousands of polyps from the second decade of life onwards. However, there is also phenotypic variability within FAP families with the same underlying gene defect, suggesting that beside the $A P C$ genotype, other factors also play a role in determining the severity of polyposis and the risk of CRC.

Both environmental and genetic factors are known to influence CRC risk [3]. To date, several single nucleotide polymorphisms (SNPs) that show an association with sporadic CRC have been identified by genome-wide association studies (GWAS) [4-10]. Furthermore, gene-environmental interactions may play a role in the effect of SNPs on CRC predisposition [11].

Two of these CRC-associated SNPs (rs16892766 and rs3802842) have been shown to be significantly associated with the risk of CRC and/or age of CRC development in patients with Lynch syndrome [12-14].

We hypothesized that SNPs associated with sporadic CRC may play a role in polyp formation in patients with a germline $A P C$ mutation. In the present study, we assessed whether known CRC-associated SNPs influence the disease phenotype in patients with a germline $A P C$ mutation.

\section{Methods}

\section{Patients}

A total of 419 patients from 182 families with a proven germline $A P C$ mutation were selected from the polyposis database of the Netherlands Foundation for the Detection of Hereditary Tumors. All patients gave informed consent for registration in the database and for use of their medical data for research purposes. All patients had also given written consent for use of their DNA in further institutional ethics-approved research into their condition before the study. The following data were collected: gender, mode of diagnosis (symptomatic or by screening), age at diagnosis of polyposis and CRC, cumulative number of colorectal adenomas, age at colorectal surgery, date and status of last follow-up. Based on the APC mutation site, patients were categorized into attenuated, intermediate or severe genotype groups, as described in the introduction [2].

\section{Genotyping of SNPs}

DNA was extracted from peripheral lymphocytes using an automated procedure (Gentra Systems, Minneapolis, USA) and quantified using Picogreen (Invitrogen, California, USA). Genotyping of the SNPs was performed with the KASPar genotyping system, and outsourced to KBioscience (http://www.kbioscience.co.uk).

\section{Statistical analysis}

The Hardy-Weinberg equilibrium of the SNPs was first tested using PLINK, version 1.07 [15]. Further analyses were performed using PASW Statistics 20. The patients were categorized according to the number of colorectal adenomas. We defined two groups: the first group with less than 100 adenomas, and the second group with 100 or more adenomas. The allele frequency of the SNPs was compared between the two groups. To assess association between phenotype and SNP, genotypic odds ratios (OR) and $95 \%$ confidence intervals (CI) were computed using the Generalized Estimating Equation, with exchangeable as working covariance structure for observations within families. A general model for the risk alleles was used for assessing statistical significance, where a dominant model was used in case of rare alleles. As a second step, we also fitted dominant and recessive models to provide further information. For testing, Wald tests were applied. APC mutation site, categorized as genotype group, was included in the model as a covariate. For all statistical analysis, a $p$ value of $<0.05$ was considered to show a trend of association. When Bonferroni multiple testing correction was applied for 15 SNPs at thirteen susceptibility loci, $p<0.004$ should be considered as cut off point for significance.

\section{Results}

A total of 419 APC mutation-positive patients were included, of which 188 (44.9\%) had more than 100 colorectal adenomas. The clinical and demographic characteristics of the study subjects are shown in Table 1. 
Regarding differences between groups, more patients with $>100$ colorectal adenomas $(38 \%)$ were symptomatic on diagnosis compared to the other group (15\%). In addition, the frequency of CRC in the $>100$ adenoma group was significantly higher than the other group. About $75 \%$ of patients from both phenotype groups had an intermediate phenotype but the proportion of patients with mutations belonging to the attenuated genotype group was twice as high in $<100$ adenoma as the $>100$ adenoma group (Table 1).

Of the 16 SNPs tested, fifteen SNPs were in HardyWeinberg equilibrium (Table 2). One SNP, rs4939827, showed borderline significant deviance and was excluded from further analyses.

The association of all 15 SNPs with disease phenotype in APC mutation carriers was modelled by Generalized Estimating Equilibrium with exchangeable variance structure. Allelic distribution, genotypic ORs and the corresponding $95 \%$ CIs for each SNP are shown in Table 3 (general inheritance model) and Fig. 1 (dominant and recessive inheritance models). Due to the low number of patients with the CC genotype for rs16892766, the genotypic OR for the CC could not be estimated and therefore the dominant model was applied.

For rs16892766, carriage of the $\mathrm{C}$ allele showed a trend of association with a more severe phenotype (OR 1.71, $95 \%$ CI 1.05-2.76, $p=0.03$, dominant model). At $11 \mathrm{q} 23.1$ (rs3802842), a borderline association was observed in the codominant inheritance model (Wald 2df $p$ value $=0.02$ ), and when tested for the recessive and dominant models of inheritance, carriers of the risk allele of this SNP were also more frequent in the $\geq 100$ polyp group (OR 1.51, $95 \%$ CI 1.03-2.22, $p=0.04$, dominant model). The other SNPs showed no associations.

When the joint association of the two SNPs (rs16892766 and rs3802842) was tested, both remained borderline significant using dominant mode of inheritance ( $p=0.04$ and $p=0.03$, respectively), however the interaction of the two SNPs was not significant $(p=0.80)$.

When the total number of sporadic CRC risk alleles in individuals of both groups was compared, the mean number of risk alleles was similar (mean of 13.11 risk alleles for the $<100$ and 12.90 for the $\geq 100$ group).

\section{Discussion}

In this study, we examined the role of CRC-associated SNPs in disease phenotype in APC mutation carriers. Although a correlation between the mutation site in the $A P C$ gene and the phenotype of FAP is well-established [2], the phenotypic variability observed in patients with the same underlying gene defect suggests that other factors must play a role in modifying disease expression in $A P C$ mutation carriers. The role of modifier genes in disease severity in FAP patients has been investigated and several modifiers, such as $\mathrm{N}$-acetyl transferases, have been suggested [16-19].
Table 1 Clinical and demographic characteristics of 419 APC mutation carriers

\begin{tabular}{|c|c|c|}
\hline & $\begin{array}{l}<100 \text { adenomas } \\
(\mathrm{N}=231)\end{array}$ & $\begin{array}{l}\geq 100 \text { adenomas } \\
(\mathrm{N}=188)\end{array}$ \\
\hline \multicolumn{3}{|l|}{ Gender } \\
\hline Male $(\%)$ & $111(48 \%)$ & $99(53 \%)$ \\
\hline \multicolumn{3}{|l|}{ Polyposis } \\
\hline Mean age at diagnosis, years & 26.5 & 27.6 \\
\hline \multicolumn{3}{|l|}{ Mode of diagnosis } \\
\hline Symptomatic (\%) & $34(15 \%)$ & $72(38 \%)$ \\
\hline Screening $(\%)$ & $197(85 \%)$ & $116(62 \%)$ \\
\hline $\mathrm{CRC}(\%)$ & $19(8 \%)$ & $30(16 \%)$ \\
\hline Mean age at CRC, years (range) & 43.4 & 40.4 \\
\hline \multicolumn{3}{|l|}{ Mutation group } \\
\hline Attenuated $(\%)$ & $50(22 \%)$ & $20(11 \%)$ \\
\hline Intermediate $(\%)$ & $172(74 \%)$ & $141(75 \%)$ \\
\hline Severe $(\%)$ & $9(4 \%)$ & $27(14 \%)$ \\
\hline \multicolumn{3}{|l|}{ Last follow-up } \\
\hline Age, years & 34.7 & 40.4 \\
\hline \multicolumn{3}{|l|}{ Status at last follow-up } \\
\hline Alive $(\%)$ & $221(96 \%)$ & $165(88 \%)$ \\
\hline Dead due to CRC (\%) & $9(4 \%)$ & $14(7 \%)$ \\
\hline Dead due to other cause $(\%)$ & $1(0.4 \%)$ & $9(5 \%)$ \\
\hline
\end{tabular}


Table 2 Test for Hardy-Weinberg equilibrium

\begin{tabular}{|c|c|c|c|c|c|c|c|}
\hline SNP & $\begin{array}{l}\text { Chromosome } \\
\text { region }\end{array}$ & $\begin{array}{l}\text { Alleles } \\
\text { major/minor }\end{array}$ & $\begin{array}{l}\text { Risk } \\
\text { allele }\end{array}$ & $\begin{array}{l}\text { HWE } \\
\text { P value }\end{array}$ & $\mathrm{MAF}^{\mathrm{a}}$ (allele) & Gene & Reference \\
\hline rs6691170 & $1 \mathrm{q} 41$ & $\mathrm{G} / \mathrm{T}$ & $\mathrm{T}$ & 0.2182 & $0.321(\mathrm{~T})$ & DUSP10 & [9] \\
\hline rs6687758 & $1 q 41$ & $\mathrm{~A} / \mathrm{G}$ & G & 0.1461 & $0.160(\mathrm{G})$ & DUSP10 & [9] \\
\hline rs10936599 & $3 q 26.2$ & $\mathrm{C} / \mathrm{T}$ & $\mathrm{C}$ & 0.8902 & $0.229(\mathrm{~T})$ & $M Y N N$ & [9] \\
\hline rs16892766 & $8 \mathrm{q} 23.3$ & $\mathrm{~A} / \mathrm{C}$ & $\mathrm{C}$ & 0.5592 & $0.091(\mathrm{C})$ & EIF3H & [4] \\
\hline rs6983267 & $8 \mathrm{q} 24.21$ & $\mathrm{G} / \mathrm{T}$ & G & 0.2798 & $0.461(\mathrm{~T})$ & $M Y C$ & {$[5]$} \\
\hline rs10795668 & 10 p14 & G/A & G & 0.1723 & $0.311(\mathrm{~A})$ & Unknown & \\
\hline rs3802842 & $11 q 23.1$ & $\mathrm{~A} / \mathrm{C}$ & $\mathrm{C}$ & 0.6216 & $0.265(\mathrm{C})$ & POU2AF1 & [6] \\
\hline rs7136702 & $12 q 13.13$ & $\mathrm{C} / \mathrm{T}$ & $\mathrm{T}$ & 0.8298 & $0.346(\mathrm{~T})$ & $L A R P 4$ & [9] \\
\hline rs11169552 & $12 q 13.13$ & $\mathrm{C} / \mathrm{T}$ & $\mathrm{C}$ & 0.6966 & $0.247(\mathrm{~T})$ & $D I P 2 B$ & [9] \\
\hline rs4444235 & $14 q 22.2$ & $\mathrm{~T} / \mathrm{C}$ & $\mathrm{C}$ & 0.2362 & $0.432(\mathrm{C})$ & $B M P 4$ & [7] \\
\hline rs4779584 & $15 q 13.3$ & $\mathrm{C} / \mathrm{T}$ & $\mathrm{T}$ & 1 & $0.159(\mathrm{~T})$ & GREM1 & {$[8]$} \\
\hline rs9929218 & $16 q 22.1$ & G/A & G & 0.4207 & $0.304(\mathrm{~A})$ & $\mathrm{CDHI}$ & [7] \\
\hline rs4939827 & $18 \mathrm{q} 21.1$ & $\mathrm{C} / \mathrm{T}$ & $\mathrm{T}$ & 0.04911 & $0.435(\mathrm{~T})$ & SMAD7 & {$[10]$} \\
\hline rs 10411210 & $19 q 13.11$ & $\mathrm{C} / \mathrm{T}$ & $\mathrm{C}$ & 0.07355 & $0.127(\mathrm{~T})$ & RHPN2 & [7] \\
\hline rs961253 & $20 \mathrm{p} 12.3$ & $\mathrm{C} / \mathrm{A}$ & A & 0.1397 & $0.311(\mathrm{~A})$ & $B M P 2$ & [7] \\
\hline rs4925386 & $20 \mathrm{q} 13.33$ & $\mathrm{C} / \mathrm{T}$ & $\mathrm{C}$ & 0.4955 & $0.311(\mathrm{~T})$ & LAMA5 & [9] \\
\hline
\end{tabular}

${ }^{a}$ Minor allele frequency (MAF) in patients included in this study

In recent years, several SNPs have been identified that influence CRC risk in the general population. In this study, we investigated whether these SNPs influence the phenotype of patients carrying a pathogenic $A P C$ mutation. Two variants were found to be associated with the disease phenotype: under a dominant inheritance model, the $\mathrm{C}$ alleles of both rs16892766 and rs3802842 showed a trend of association with a phenotype of more than 100 adenomas.

A previous study demonstrated that individuals carrying the risk (C) allele of rs16892766 (8q23.3) present with a more advanced stage of CRC at diagnosis [20]. Tomlinson et al. found that the risk allele of rs16892766 was associated with CRC in younger individuals [4]. In other studies, the risk allele of rs 16892766 correlated with an increased CRC risk and/or age of CRC diagnosis in Lynch syndrome [12-14]. In our study, the C allele of this SNP was associated with a more severe FAP phenotype ( $\geq 100$ polyps) in $A P C$ mutation carriers. The higher polyp number associated with the $C$ allele of rs16892766 could be explained by the location of this SNP in the EIF3H gene, which increases cell proliferation, growth, and survival when overexpressed. However, Carvajal-Carmona et al. [21] suggested that UTP23, rather than $E I F 3 H$, is the most likely target of the genetic variation associated with CRC in the $8 \mathrm{q} 23.3$ region, but also proposed that both of these genes may play a role in CRC development, given that they have related roles in mRNA translation. UTP23 is thought to be involved in ribosome biogenesis [22].
The risk allele of rs3802842 (11q23.1) has been associated with early-onset CRC $(<50$ years old) and a family history of CRC [20, 23]. Moreover, this SNP is also known to be associated with increased CRC risk in patients with Lynch syndrome [12-14]. A recent study described the association of rs3802842 with disease in patients with unexplained polyposis [20, 24]. In the present study, rs3802842 showed a borderline association with the more severe phenotype of $\geq 100$ polyps in the codominant model of inheritance with two degrees of freedom. When this SNP was tested under recessive and dominant inheritance models, a trend of association was observed between risk allele carriage and the $\geq 100$ polyp phenotype (dominant inheritance model). Functionally, rs3802842 is located within a gene-rich region of chromosome 11q23 that includes four open reading frames (ORFs) within $100 \mathrm{~kb}$ : COLCA1, COLCA2, POU2AF1 and C11orf53 (6). The exact function of this SNP is still unknown; one study assessed whether rs3802842 might have cis-regulatory effects on these neighbouring genes, but found no evidence for a relationship. These authors suggested that the underlying sequence change defined by this SNP might exert regulatory effects on genes mapping outside 11q23.1 [25]. Another study suggested that rs3802842 is not itself a functional SNP but is in linkage disequilibrium with a functional SNP [26].

SNPs associated with CRC susceptibility could increase $\mathrm{CRC}$ risk by promoting initiation of adenoma formation or promoting growth and/or progression from the adenoma to 


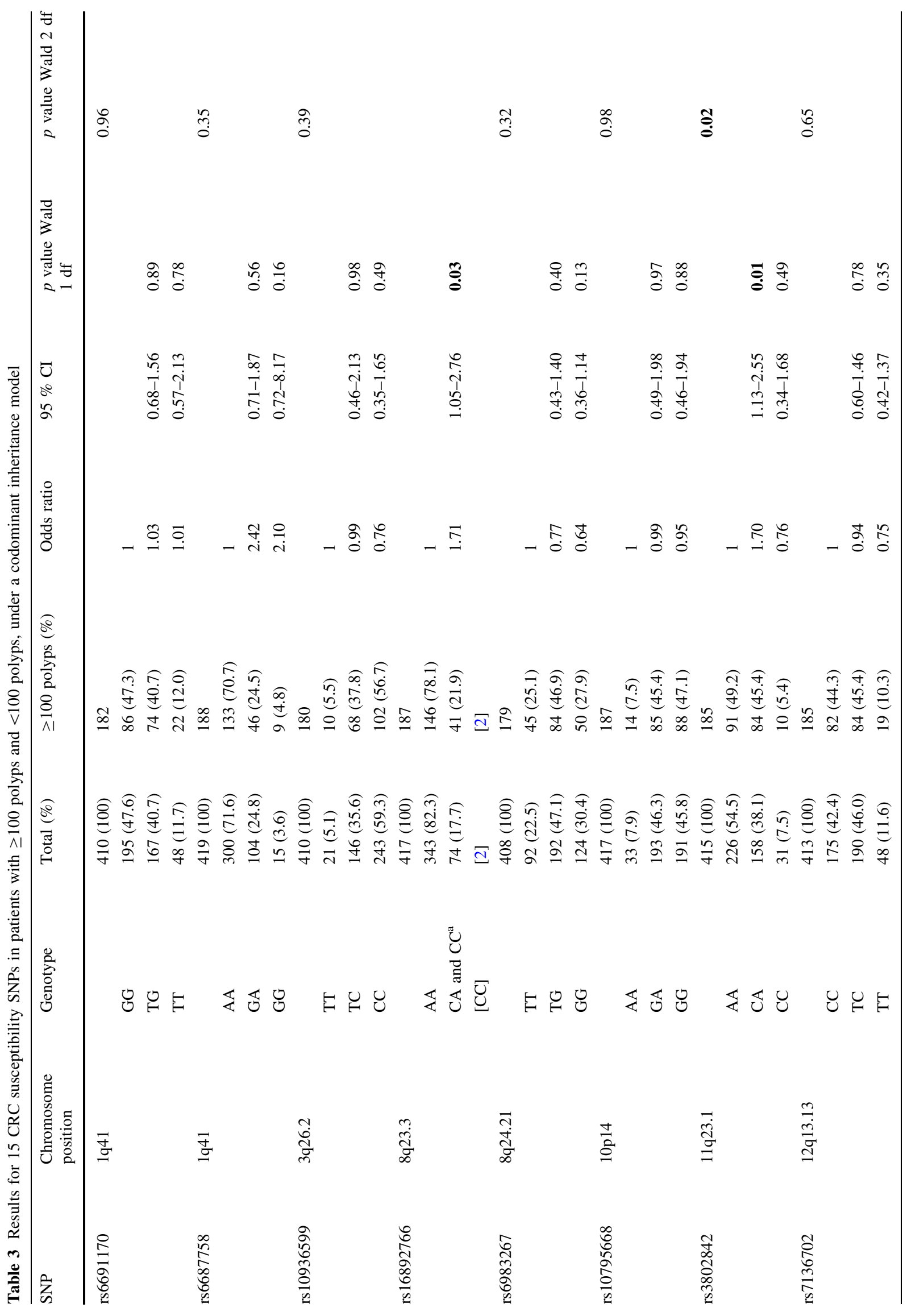




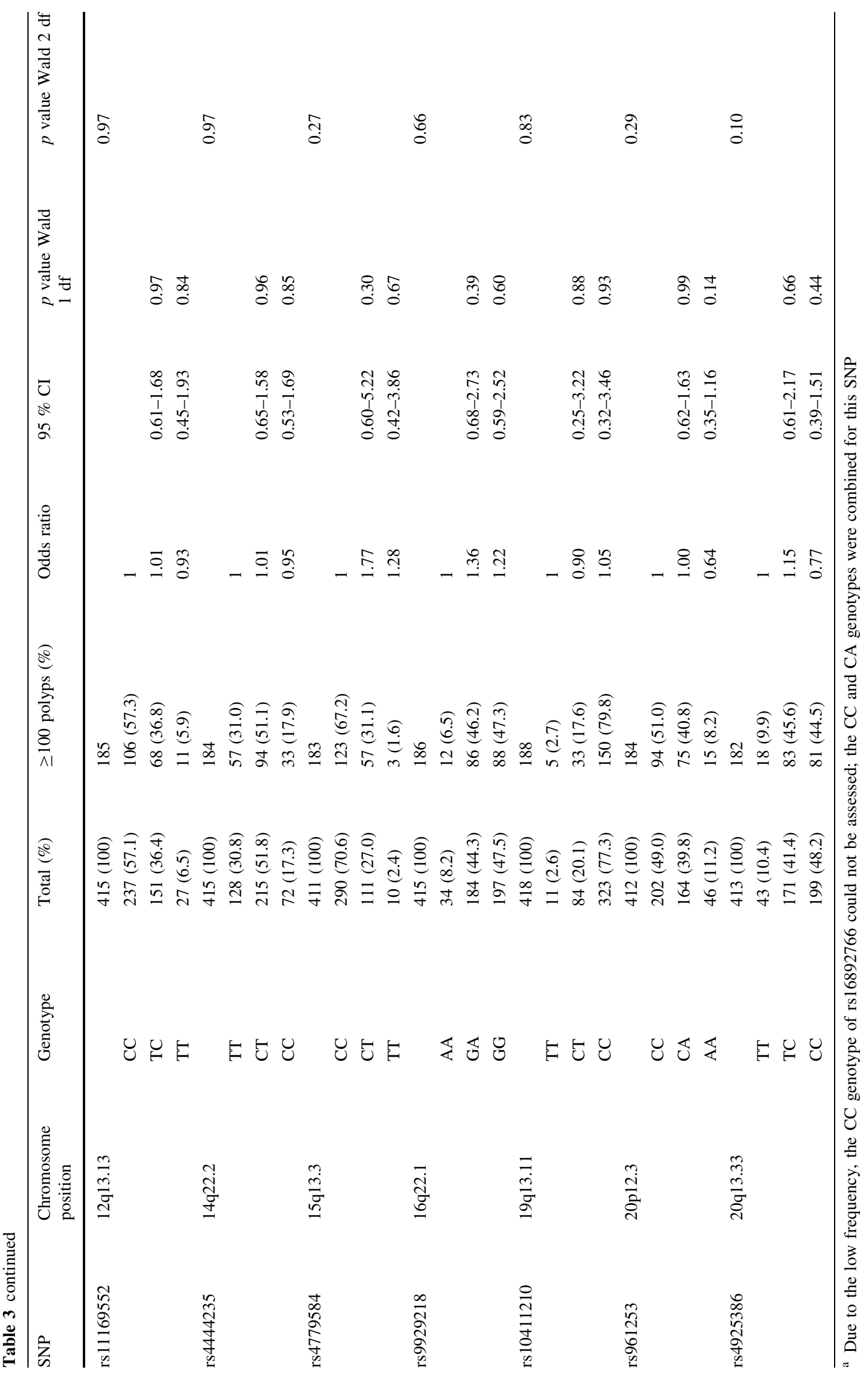



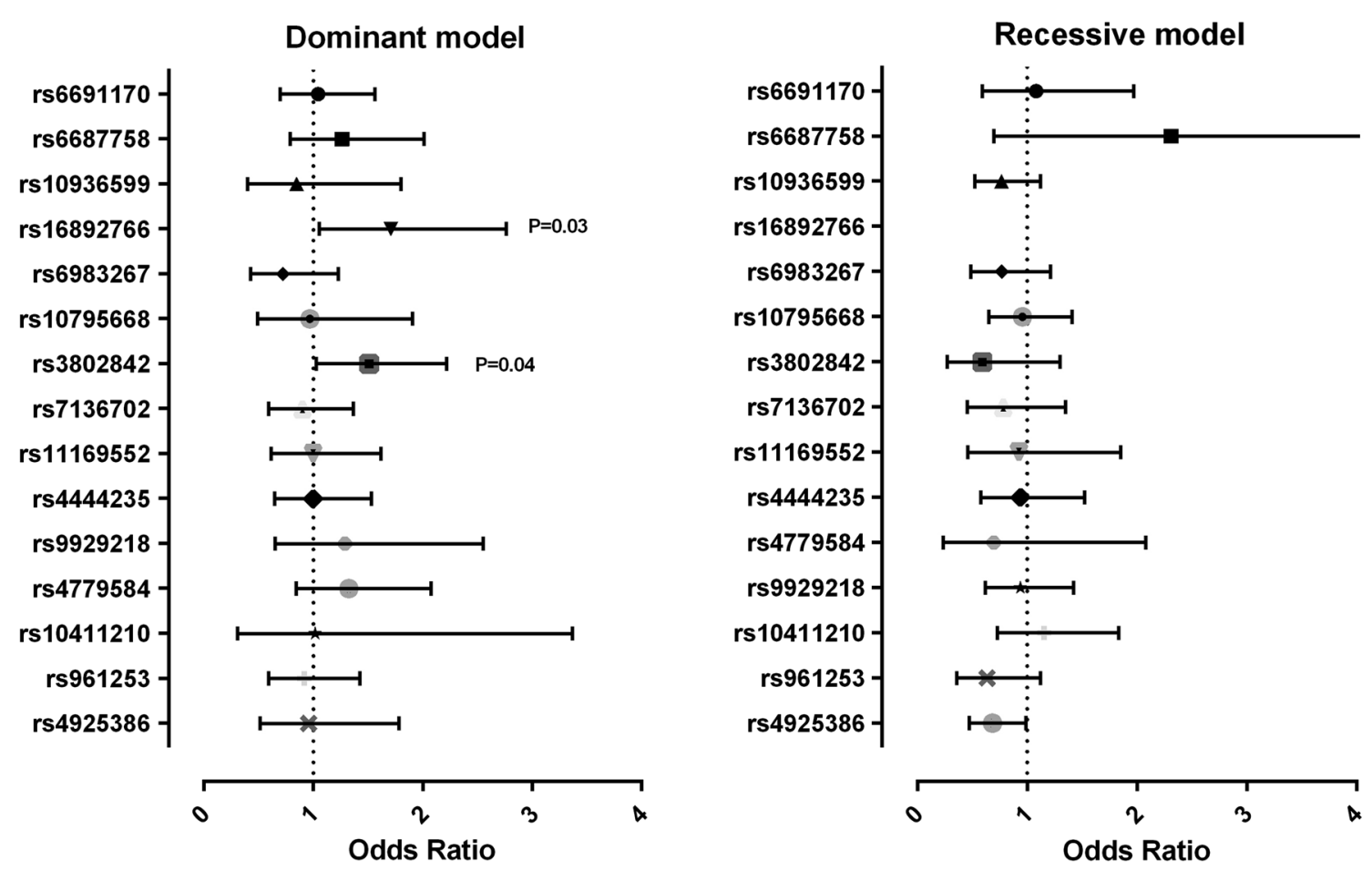

Fig. 1 Forest plot: results for 15 susceptibility SNPs in patients with $\geq 100$ polyps and $<100$ polyps, under recessive and dominant inheritance models

carcinoma stage, or be involved in both. Theoretically, initiation-promoting SNPs are expected to be more frequent in patients with multiple adenomas and in CRC-free patients with adenoma. A recent study found eight known CRC-associated SNPs, including rs3802842, to be overrepresented in CRC-free patients with adenoma [27]. In relation to the effect of SNPs on the above-mentioned stages, only the association of a CRC-associated SNP at 8q24.21 (rs6983267) with adenoma multiplicity and the association of rs3802842 and rs4779584 with unexplained polyposis have been described to date [6, 24]. Based on these literature reports and the outcome of our study, we hypothesize that rs3802842 is involved in the initiation stage of adenoma development.

An association between the total number of CRC-associated risk alleles and familial CRC has been suggested in two previous studies [28, 29]. Therefore, we investigated whether there was a difference in total number of risk alleles between the two groups. We found the mean number of risk alleles to be similar in the two groups.

Recently, one study examined the severity of polyposis in 64 patients and found no evidence of association in any of their tested SNPs [30], however as stated by TalsethPalmer et al. [31] large cohorts are required to examine the role of modifiers in severity of disease phenotype in FAP patients.

In conclusion, we identified two CRC-associated SNPs, rs16892766 (8q23.3) and rs3802842 (11q23.1), which show an association with adenoma number in $A P C$ mutation carriers. In order to evaluate and confirm the effect of these SNPs on the phenotype of FAP, further studies with larger sample sizes are now recommended.

Acknowledgments Association of International Cancer Research, Grant 2010-0619 and Dutch Cancer Society, Grant KWF-UL-20104656.

Open Access This article is distributed under the terms of the Creative Commons Attribution 4.0 International License (http://crea tivecommons.org/licenses/by/4.0/), which permits unrestricted use, distribution, and reproduction in any medium, provided you give appropriate credit to the original author(s) and the source, provide a link to the Creative Commons license, and indicate if changes were made.

\section{References}

1. Debinski HS, Love S, Spigelman AD, Phillips RK (1996) Colorectal polyp counts and cancer risk in familial adenomatous polyposis. Gastroenterology 110(4):1028-1030

2. Nieuwenhuis MH, Vasen HF (2007) Correlations between mutation site in APC and phenotype of familial adenomatous polyposis (FAP): a review of the literature. Crit Rev Oncol Hematol 61(2):153-161. doi:10.1016/j.critrevonc.2006.07.004

3. Watson AJ, Collins PD (2011) Colon cancer: a civilization disorder. Dig Dis 29(2):222-228. doi:10.1159/000323926

4. Tomlinson IP, Webb E, Carvajal-Carmona L et al (2008) A genome-wide association study identifies colorectal cancer susceptibility loci on chromosomes 10p14 and 8q23.3. Nat Genet 40(5):623-630. doi:10.1038/ng.111 
5. Tomlinson I, Webb E, Carvajal-Carmona L et al (2007) A genome-wide association scan of tag SNPs identifies a susceptibility variant for colorectal cancer at 8q24.21. Nat Genet 39(8):984-988. doi:10.1038/ng2085

6. Tenesa A, Farrington SM, Prendergast JG et al (2008) Genomewide association scan identifies a colorectal cancer susceptibility locus on 11q23 and replicates risk loci at $8 \mathrm{q} 24$ and $18 \mathrm{q} 21$. Nat Genet 40(5):631-637. doi:10.1038/ng.133

7. Study C, Houlston RS, Webb E et al (2008) Meta-analysis of genome-wide association data identifies four new susceptibility loci for colorectal cancer. Nat Genet 40(12):1426-1435. doi:10. 1038/ng.262

8. Jaeger E, Webb E, Howarth K et al (2008) Common genetic variants at the CRAC1 (HMPS) locus on chromosome 15q13.3 influence colorectal cancer risk. Nat Genet 40(1):26-28. doi:10. 1038/ng.2007.41

9. Houlston RS, Cheadle J, Dobbins SE et al (2010) Meta-analysis of three genome-wide association studies identifies susceptibility loci for colorectal cancer at 1q41,3q26.2, 12q13.13 and 20q13.33. Nat Genet 42(11):973-977. doi:10.1038/ng.670

10. Broderick P, Carvajal-Carmona L, Pittman AM et al (2007) A genome-wide association study shows that common alleles of SMAD7 influence colorectal cancer risk. Nat Genet 39(11):1315-1317. doi:10.1038/ng.2007.18

11. Hutter CM, Chang-Claude J, Slattery ML et al (2012) Characterization of gene-environment interactions for colorectal cancer susceptibility loci. Cancer Res 72(8):2036-2044. doi:10.1158/ 0008-5472.CAN-11-4067

12. Wijnen JT, Brohet RM, van Eijk R et al (2009) Chromosome $8 \mathrm{q} 23.3$ and 11q23.1 variants modify colorectal cancer risk in Lynch syndrome. Gastroenterology 136(1):131-137. doi:10. 1053/j.gastro.2008.09.033

13. Talseth-Palmer BA, Scott RJ, Vasen HF, Wijnen JT (2012) $8 \mathrm{q} 23.3$ and $11 \mathrm{q} 23.1$ as modifying loci influencing the risk for CRC in Lynch syndrome. Eur J Hum Genet 20(5):487-488. doi:10.1038/ejhg.2011.232 (author reply 8)

14. Talseth-Palmer BA, Brenne IS, Ashton KA et al (2011) Colorectal cancer susceptibility loci on chromosome 8q23.3 and 11q23.1 as modifiers for disease expression in Lynch syndrome. J Med Genet 48(4):279-284. doi:10.1136/jmg.2010.079962

15. Purcell S, Neale B, Todd-Brown K et al (2007) PLINK: a tool set for whole-genome association and population-based linkage analyses. Am J Hum Genet 81(3):559-575. doi:10.1086/519795

16. Yanaru-Fujisawa R, Matsumoto T, Kukita $Y$ et al (2007) Impact of Phospholipase A2 group IIa gene polymorphism on phenotypic features of patients with familial adenomatous polyposis. Dis Colon Rectum 50(2):223-231. doi:10.1007/s10350-006-0780-2

17. Houlston R, Crabtree M, Phillips R, Crabtree M, Tomlinson I (2001) Explaining differences in the severity of familial adenomatous polyposis and the search for modifier genes. Gut 48(1): $1-5$

18. Crabtree MD, Fletcher C, Churchman M et al (2004) Analysis of candidate modifier loci for the severity of colonic familial adenomatous polyposis, with evidence for the importance of the $\mathrm{N}$-acetyl transferases. Gut 53(2):271-276

19. Crabtree MD, Tomlinson IP, Hodgson SV, Neale K, Phillips RK, Houlston RS (2002) Explaining variation in familial adenomatous polyposis: relationship between genotype and phenotype and evidence for modifier genes. Gut 51(3):420-423

20. Abuli A, Bessa X, Gonzalez JR et al (2010) Susceptibility genetic variants associated with colorectal cancer risk correlate with cancer phenotype. Gastroenterology 139(3):788-796. doi:10. 1053/j.gastro.2010.05.072

21. Carvajal-Carmona LG, Cazier JB, Jones AM et al (2011) Finemapping of colorectal cancer susceptibility loci at $8 \mathrm{q} 23.3$, 16q22.1 and 19q13.11: refinement of association signals and use of in silico analysis to suggest functional variation and unexpected candidate target genes. Hum Mol Genet 20(14): 2879-2888. doi:10.1093/hmg/ddr190

22. Bleichert F, Granneman S, Osheim YN, Beyer AL, Baserga SJ (2006) The PINc domain protein Utp24, a putative nuclease, is required for the early cleavage steps in 18S rRNA maturation. Proc Natl Acad Sci USA 103(25):9464-9469. doi:10.1073/pnas. 0603673103

23. Giraldez MD, Lopez-Doriga A, Bujanda L et al (2012) Susceptibility genetic variants associated with early-onset colorectal cancer. Carcinogenesis 33(3):613-619. doi:10.1093/carcin/ bgs009

24. Hes FJ, Ruano D, Nieuwenhuis M et al (2014) Colorectal cancer risk variants on $11 \mathrm{q} 23$ and $15 \mathrm{q} 13$ are associated with unexplained adenomatous polyposis. J Med Genet 51(1):55-60. doi:10.1136/ jmedgenet-2013-102000

25. Pittman AM, Webb E, Carvajal-Carmona L et al (2008) Refinement of the basis and impact of common 11q23.1 variation to the risk of developing colorectal cancer. Hum Mol Genet 17(23):3720-3727. doi: $10.1093 / \mathrm{hmg} / \mathrm{ddn} 267$

26. Biancolella M, Fortini BK, Tring S et al (2014) Identification and characterization of functional risk variants for colorectal cancer mapping to chromosome 11q23.1. Hum Mol Genet 23(8):2198-2209. doi:10.1093/hmg/ddt584

27. Carvajal-Carmona LG, Zauber AG, Jones AM et al (2013) Much of the genetic risk of colorectal cancer is likely to be mediated through susceptibility to adenomas. Gastroenterology 144(1):53-55. doi:10.1053/j.gastro.2012.09.016

28. Middeldorp A, Jagmohan-Changur S, van Eijk R et al (2009) Enrichment of low penetrance susceptibility loci in a Dutch familial colorectal cancer cohort. Cancer Epidemiol Biomarkers Prev 18(11):3062-3067. doi:10.1158/1055-9965.EPI-09-0601

29. Niittymaki I, Kaasinen E, Tuupanen S et al (2010) Low-penetrance susceptibility variants in familial colorectal cancer. Cancer Epidemiol Biomarkers Prev 19(6):1478-1483. doi:10.1158/10559965.EPI-09-1320

30. Cheng TH, Gorman M, Martin L et al (2015) Common colorectal cancer risk alleles contribute to the multiple colorectal adenoma phenotype, but do not influence colonic polyposis in FAP. Eur J Hum Genet 23(2):260-263. doi:10.1038/ejhg.2014.74

31. Talseth-Palmer BA, Wijnen JT, Andreassen EK et al (2013) The importance of a large sample cohort for studies on modifier genes influencing disease severity in FAP patients. Hered Cancer Clin Pract 11(1):20. doi:10.1186/1897-4287-11-20 